\title{
Using a sulfur autotrophic fluidized bed reactor for simultaneous perchlorate and nitrate removal from water: $\mathrm{S}$ disproportionation prediction and system optimization
}

\author{
Yongde $\mathrm{Liu}^{1}$, Yang $\mathrm{Liu}^{1}$, Qiaochong $\mathrm{He}^{1}$, Qi Li ${ }^{1}$, Dongjin Wan ${ }^{1}$, and Jia Zhou ${ }^{1}$ \\ ${ }^{1}$ Henan University of Technology
}

October 8, 2020

\begin{abstract}
A sulfur autotrophic fluidized bed reactor was established to overcome mass transfer problems and shorten the co-reduction time for perchlorate and nitrate from aqueous solution. Response surface methodology (RSM) was used to predict the subsequent extent of sulfur $(\mathrm{S})$ disproportionation based on three variable parameters, namely the hydraulic retention time (HRT), co-existing nitrate concentration $\left(\mathrm{C}_{-}\right.$\inf $\rrbracket[?]\left[\left[\left[\left[\mathrm{NO} \rrbracket \_3^{\wedge}-\mathrm{N} \rrbracket\right)\right.\right.\right.$ ) and recirculation ratio $(\mathrm{R})$. The extent of sulfur (S) disproportionation was determined by sulfate generation and alkalinity consumption. RSM results show that a long HRT and high R promoted whereas co-existing nitrate inhibited sulfate production from $\mathrm{S}$ disproportionation. For complete perchlorate and nitrate reduction $(>98.45 \%)$ with relatively low sulfate generation $(236.07 \mathrm{mg} / \mathrm{L})$, the optimal HRT, C_ 『inf \[?][[[[NO』_3^-N】and $\mathrm{R}$ were $0.50 \mathrm{~h}, 10 \mathrm{mg} / \mathrm{L}$ and 14, respectively. High-throughput sequencing revealed that Chlorobaculum was associated with $\mathrm{S}$ disproportionation while the abundance of Sulfurovum, an effective denitrification/perchlorate reducing bacteria, decreased over the height of the reactor.
\end{abstract}

\section{Hosted file}

Main Document.pdf available at https://authorea.com/users/365495/articles/485576-usinga-sulfur-autotrophic-fluidized-bed-reactor-for-simultaneous-perchlorate-and-nitrateremoval-from-water-s-disproportionation-prediction-and-system-optimization 
(a)
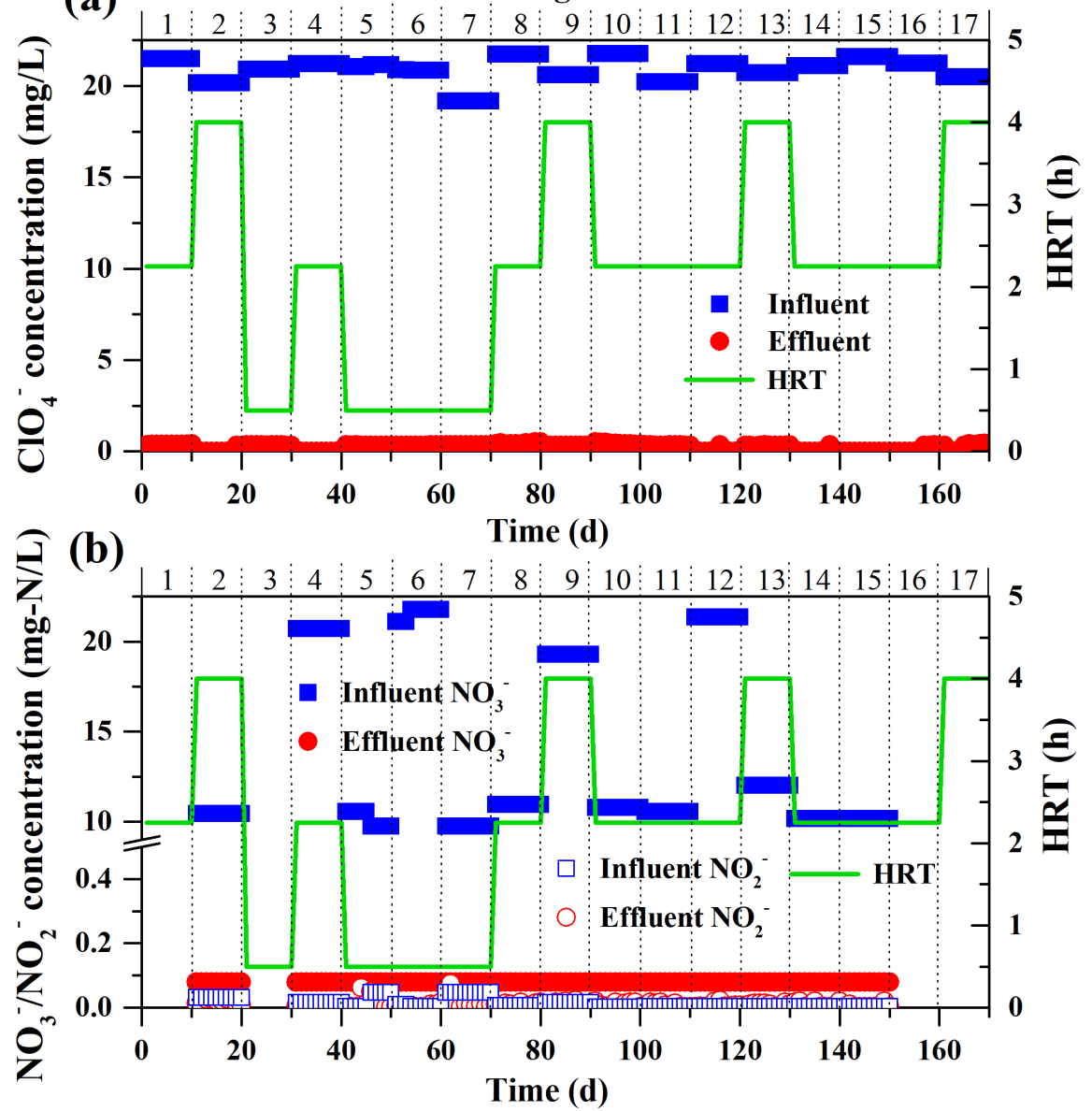

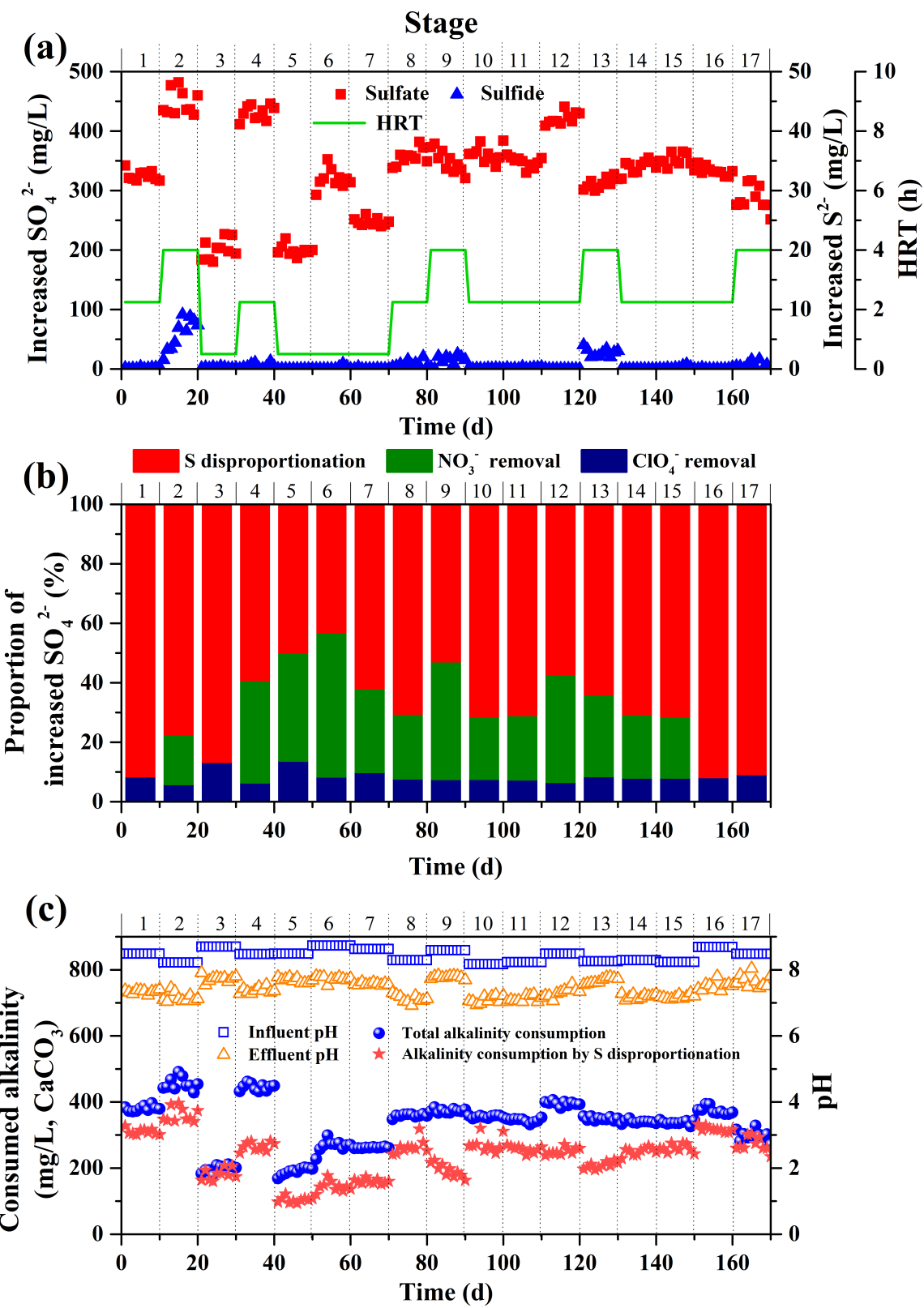

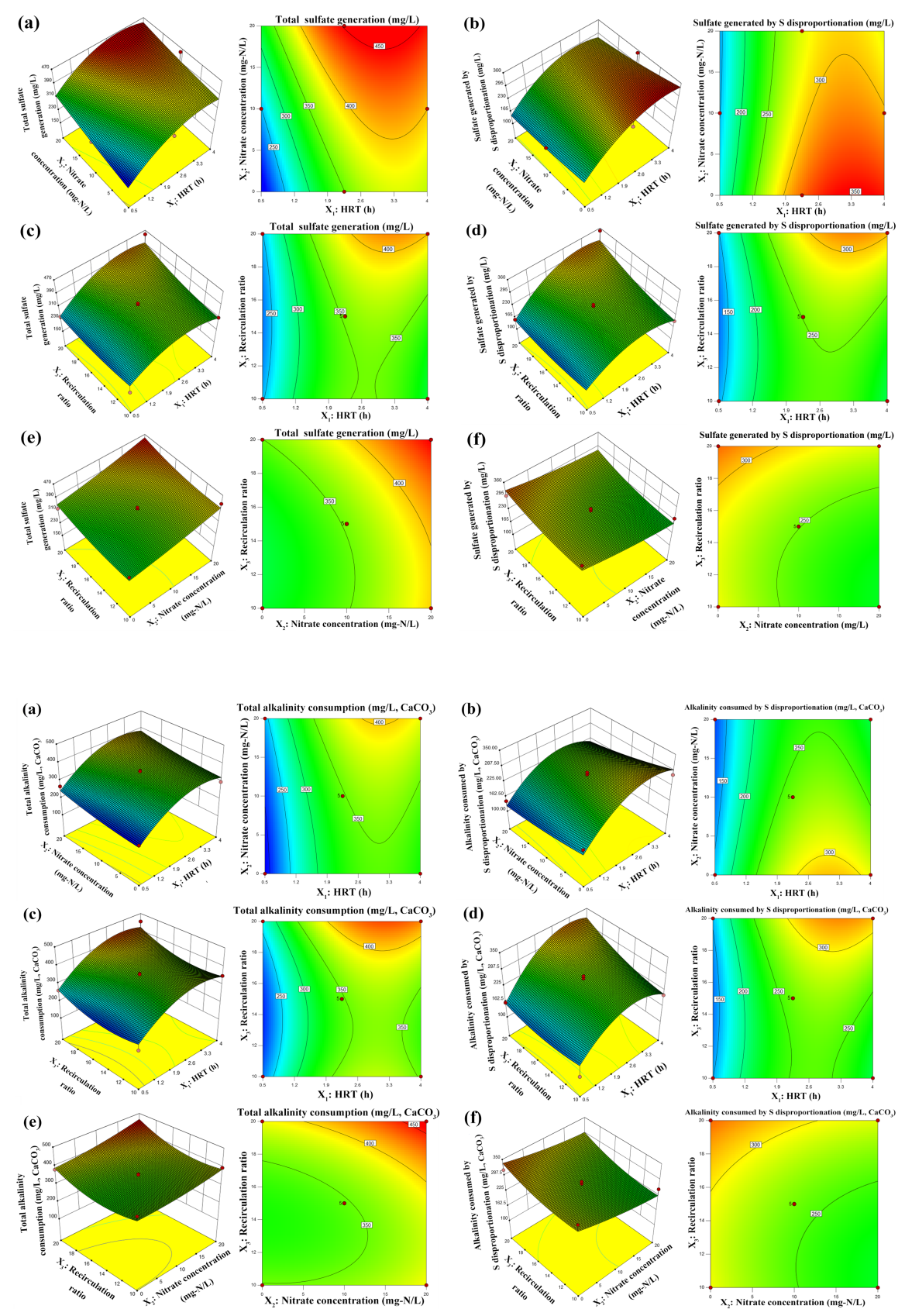

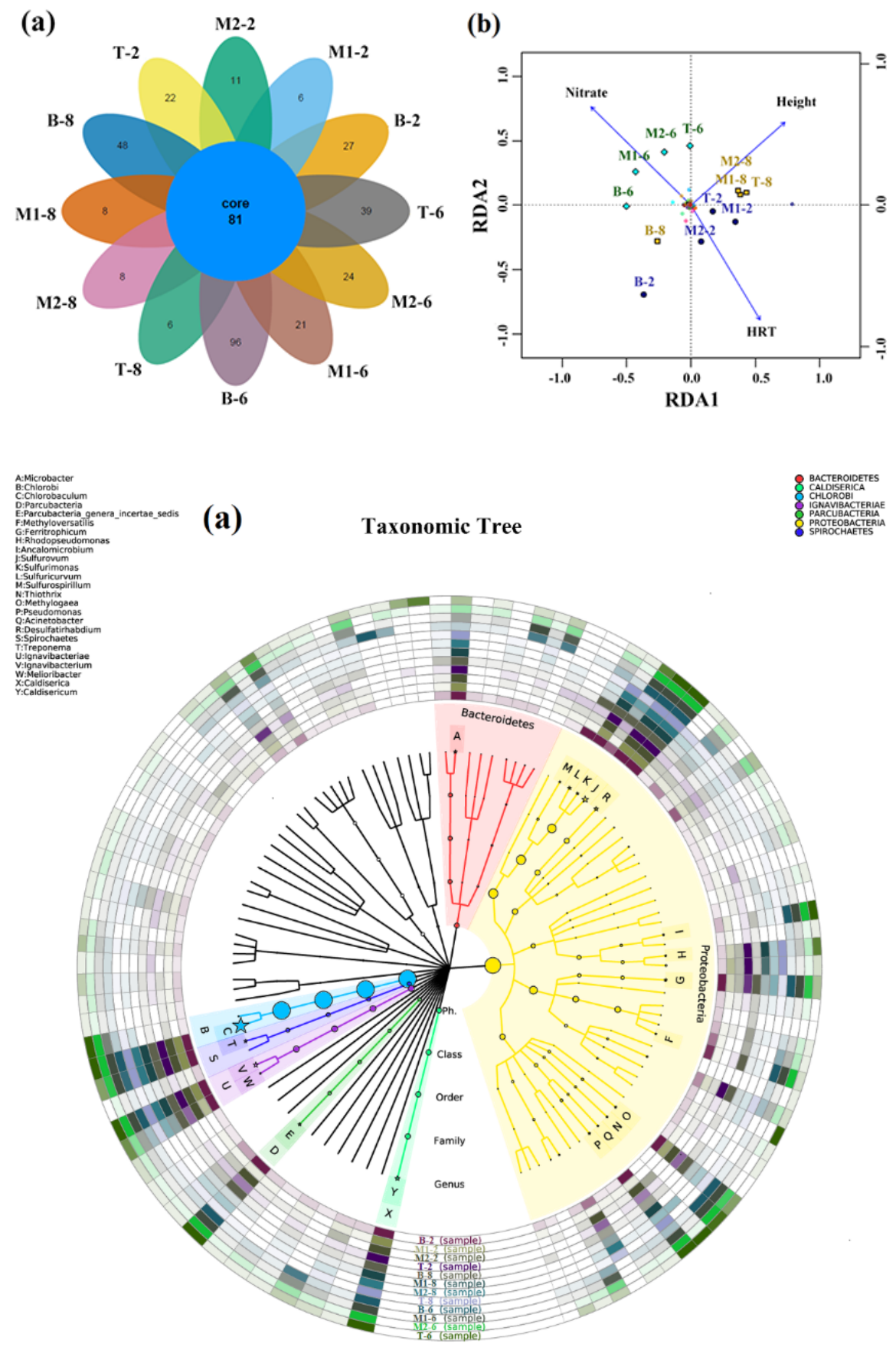
(b)
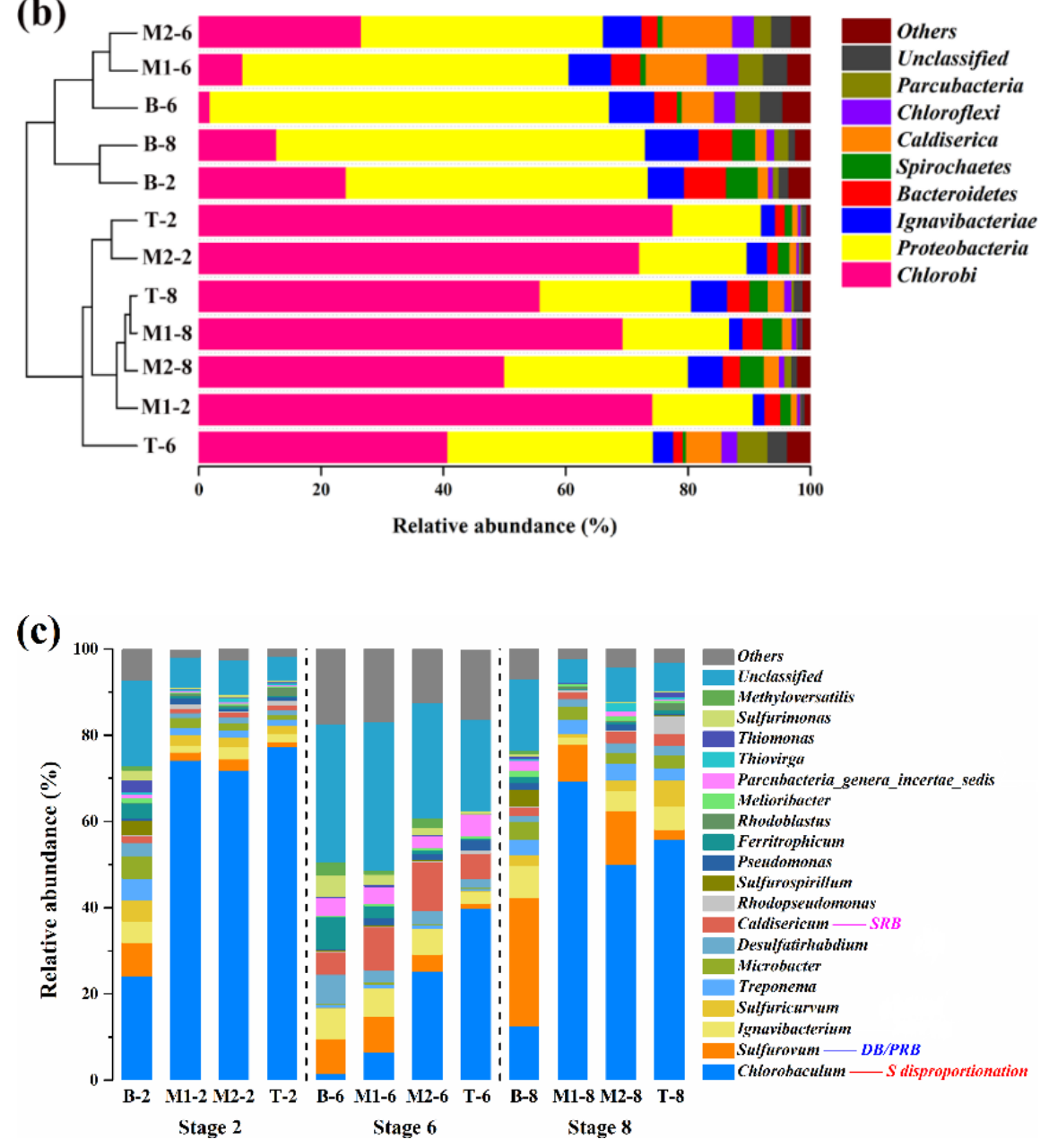